\title{
O papel da literatura infantil na formação da criança: concepções e práticas vivenciadas no PIBID em uma escola da Baixada Fluminense, RJ The children's literature role in the formation of children: conceptions and practices experienced in $P I B I D$ in a Baixada Fluminense, $R J$ school
}

\author{
Jonas Alves da Silva Junior* \\ Michele dos Santos Melo Fernandes*
}

DOI: http://dx.doi.org/10.20435/2318-1982-2016-v.21-n.42(07)

\begin{abstract}
Resumo
O presente trabalho foi fruto de experiência vivenciada no Programa Institucional de Bolsas de Iniciação à Docência (PIBID), no ano de 2014, no Curso de Pedagogia da UFRRJ. A metodologia - de cunho qualitativo - foi calcada na observação de uma turma do quinto ano do Ensino Fundamental de uma escola pública de um município da Baixada Fluminense - Rio de Janeiro, e na entrevista do professor implementador de leitura da escola-campo. $O$ interesse pela pesquisa surgiu a partir das dificuldades enfrentadas pelos educadores na formação de leitores ativos e o aparente desinteresse dos educandos pela leitura no ambiente escolar. Desse modo, a pesquisa visa discutir o conceito de literatura infantil em um breve aparato histórico, o papel social e histórico da literatura infantil na formação de sujeitos criativos e autônomos e a função do educador como um propiciador de momentos significativos na aprendizagem da criança. Como referencial teórico, optamos por dialogar com autores como Frantz, Góes, Costa, Sandroni e Machado, dentre outros. Conclui-se que as atividades de literatura infantil organizadas pelo professor em sala de aula são, muitas vezes, utilizadas como recurso pedagógico desvinculado da realidade sócio-histórico-cultural dos educandos. Tais resultados evocam a importância da formação de professores na construção de educadores leitores e aptos a estabelecer uma relação com a literatura infantil com base no diálogo, na arte, na ludicidade e na criatividade.
\end{abstract}

Palavras-chave:

Literatura infantil; formação de leitor; PIBID.

\begin{abstract}
This work was the fruit of lived experience in the Institutional Scholarship Program Introduction to Teaching (PIBID), in 2014, the School of Education of UFRRJ. The methodology-a qualitative approach - was based on the observation of a class of fifth year of elementary school to a public school in a town in the Baixada Fluminense - Rio de Janeiro, and the implementer teacher interview school-field reading. The interest in research arose from the difficulties faced by educators in the formation of
\end{abstract}

\footnotetext{
* Universidade Federal Rural do Rio de Janeiro (UFRRJ), Seropédica, RJ, Brasil.
} 
active readers and the apparent disinterest of students in reading at school. Thus, the research aims to discuss the concept of children's literature in a brief historical apparatus, the social and historical role of children's literature in the formation of creative and autonomous subjects and the role of the educator as an enabling significant moments in the child's learning. As a theoretical framework, we opted for dialogue with authors Frantz, Góes, Costa, Sandroni e Machado, within others. It is concluded that the children's literature of activities organized by the teacher in the classroom are often used as unbound educational resource of socio-historical-cultural reality of the students. These results evoke the importance of teacher education in the construction of readers educators and able to establish a relationship with the children's literature based on dialogue, art, playfulness and creativity.

Key words:

Children's literature; formation reader; PIBID.

\section{INTRODUÇÃO}

A criança mistura-se com os personagens de maneira muito mais íntima do que o adulto. 0 desenrolar e as palavras trocadas atingem-na com força inefável, e quando ela se levanta está envolta pela nevasca que soprava da leitura. (Walter Benjamin)

O interesse em pesquisar o uso da literatura infantil nas escolas públicas surgiu a partir de leituras empreendidas durante o curso de Pedagogia e nos contatos com turmas do Ensino Fundamental - Anos Iniciais, da rede pública de ensino, em experiências de Estágio do mesmo curso, onde pudemos identificar o impasses do trabalho com a literatura infantil pelos educadores, assim como o pouco apreço das crianças pela leitura. Dessa forma, a partir do interesse por pesquisar o assunto e com nosso trabalho vinculado ao Programa ${ }^{1}$ Institucional

${ }^{1}$ O PIBID é uma iniciativa para o aperfeiçoamento e a valorização da formação de professores de Bolsa de Iniciação à Docência (PIBID) no ano de 2014, em que atuamos em uma escola municipal pública da Baixada Fluminense, RJ, em uma sala do quinto ano do ensino fundamental, tivemos a oportunidade de poder vivenciar mais de perto como ocorre o trabalho dos educadores com a literatura infantil em sala de aula, pois a instituição escolar onde fomos integrados possuía um trabalho voltado ao incentivo e à implementação de leitura, que será o foco do nosso estudo. Este texto, portanto, tentará compreender como acontece o trabalho já consolidado na escola,

para a educação básica. O programa concede bolsas a alunos de licenciatura participantes de projetos de iniciação à docência desenvolvidos por Instituições de Educação Superior (IES) em parceria com escolas de educação básica da rede pública de ensino. Os projetos devem promover a inserção dos estudantes no contexto das escolas públicas desde o início da sua formação acadêmica para que desenvolvam atividades didático-pedagógicas sob orientação de um docente da licenciatura e de um professor da escola. Mais informações consultar: <http://www.capes. gov.br/educacao-basica/capespibid $>$. 
identificando os pontos positivos e as dificuldades que poderemos encontrar e superar no decorrer de nossa atuação junto à unidade escolar.

Nesse sentido, o ponto inicial para elaboração do trabalho foi de revisitar a literatura especializada, de modo que pudemos depreender que o uso do lúdico foi deveras ressaltado como uma das fontes de aprendizado satisfatória para a criança. Partindo do pressuposto de que a fantasia, a imaginação e o movimento fazem parte do universo infantil, acreditamos então que uma das melhores formas de se trabalhar com a criança em sala de aula, inclusive com a literatura infantil, é por meio da ludicidade, pois, além de esta ser atrativa e prazerosa à criança, envolve o jogo, a brincadeira e o fantástico, que são elementos familiares ao universo infantil.

Escolher pesquisar o tema literatura infantil não é somente de relevância para a educação escolar, mas também é de relevância social, pois temos conhecimento de que, em muitas famílias, o gosto em ouvir histórias começa cedo na vida da criança. Esse contato com a literatura vai sendo construído desde o nascimento, na relação mãe-filho, quando esta, ao embalar o bebê, costuma cantar as cantigas de ninar ou brincar com os jogos rítmicos, entre eles, Serra, Serra, Serrador; Bão Balalão, ou quando, ainda, costuma contar ou ler diversas narrativas infantis e relatar para a criança as histórias da família. Também quando a criança, em contato com outros adultos, ou mesmo com seus pares, começa a ter conhecimento das lendas, mitos e contos da cultura popular. $E$, à medida que os estímulos do meio circundante vão se intensificando, a presença da literatura vai se ampliando e tornando-se cada vez mais frequente na vida da criança, acompanhando-a até a idade adulta.

Isso deve ser considerado relevante para a vida social de qualquer menino ou menina, pois vivemos numa sociedade letrada e de conhecimentos diversos, que demanda cada vez mais indivíduos proativos, criativos e construtores, cabendo então às instituições sociais, principalmente à escola - um dos espaços onde as crianças têm contato científico com os bens sociais e culturais socialmente produzidos - serem grandes incentivadores pelo gosto e hábito da leitura. Leitura esta que permita não só o conhecimento da realidade social, mas que possibilite sempre novas interpretações dessa realidade.

Contudo muitos são os problemas, dificuldades e equívocos enfrentados pela escola e pelos educadores em geral, na tentativa de que o educando encontre prazer no ato de ler. As táticas se manifestam desde a forma como a leitura e a literatura são apresentadas às crianças até a compreensão utilitária de leitura e literatura que ainda predomina nas instituições escolares e que refletem nas práticas pedagógicas adotadas pelos professores, quando trabalham com a literatura em sala de aula. Ou seja, parte dos professores costuma ainda utilizar estratégias e metodologias em que a concepção de literatura utilitarista e 
mantenedora ganha destaque e importância, em detrimento de uma literatura de caráter emancipatório, cujos aspectos serão abordados posteriormente, no momento da apresentação da revisão da literatura.

No entanto, para entender como acontece a implementação de leitura da literatura infantil na escola, será necessário verificar que relação o educador - que, no caso desta pesquisa, trata-se de um pedagogo implementador de leitura - tem com a literatura; que importância ele atribui à literatura infantil na formação da criança, assim como de que modo costuma utilizá-la na sala/espaço de leitura, ou seja, se esse processo acontece com a finalidade de trabalhar uma literatura que recusa o utilitário e propõe o pensamento divergente, ou com uma literatura que mantém a criança nas amarras do cotidiano, sem questioná-la e sem reelaborar sua visão de mundo.

Consideramos esta pesquisa relevante, pois poderá evidenciar a importância do uso da literatura infantil na formação de educandos críticos e transformadores da realidade, como também poderá oportunizar que as reflexões teóricas que serão apresentadas conduzam os educadores a uma compreensão mais ampla, crítica, sensível e humanizante da literatura, de modo a contribuir nas construções de práticas escolares mais efetivas para o trabalho com a literatura infantil na escola, não como matéria aprisionada, mas como expressão criadora.
Dessa forma, conforme expressa Frantz (2005, p. 31) “[...] acreditamos que uma educação transformadora e humanizante passa necessariamente pela prática da leitura e tem nela seu objetivo maior".

Neste sentido, para que haja maior compreensão do tema pesquisado, apresentaremos inicialmente uma revisão da literatura que fornece informações pertinentes ao tema e que também irá fundamentar as investigações, análises e considerações. E, em seguida, abordaremos a parte empírica da pesquisa.

\section{O DIDATISMO LITERÁRIO E O PAPEL DO EDUCADOR COM A LITERATURA INFANTIL}

Daniel Pennac (1993), em seu livro Como um romance, postula que a leitura pode acontecer de forma espontânea e prazerosa para o leitor, assim como um romance. No entanto, nos estudos desenvolvidos para esta pesquisa, ressoou uníssono entre os autores pesquisados a existência predominante da função utilitário-pedagógica da literatura destinada à criança.

Autores como Palo (2006); Peres (1997); Góes (1984); Sandroni e Machado (1998); Frantz (2005); Nery e Silva (2008) apontam a presença do didatismo e da pedagogia na literatura como forma de fazer a criança aprender a ler e a obter resultados positivos na escola, retirando dela o prazer pela leitura. Sendo assim, com uma concepção meramente didática, o educador propicia que "[...] o aluno 
não consiga perceber a leitura da literatura como uma atividade significativa e gratificante em sua vida, e por isso não se interessa por ela" (FRANTZ, 2005, p. 14).

Nery e Silva (2008) afirmam que o trabalho com a literatura não deve ser usado como estratégia de aprendizagem de conteúdos desenvolvidos, pois agindo assim fica

[...] configurando tal atividade como uma avaliação, distanciando assim a perspectiva da leitura-prazer que tem por objetivo proporcionar a exploração do processo de comunicação que a obra literária por si só já apresenta. (NERY; SILVA, 2008, p. 593-594).

No entanto o utilitarismo pedagógico no trabalho com a literatura infantil ainda funciona teimosamente presente nas práticas pedagógicas de muitos professores, encontrando-se historicamente arraigado no modelo de escola tradicional $^{2}$, em que a criança é considerada um

${ }^{2}$ Segundo a teoria de José Carlos Libâneo (2007), as tendências pedagógicas na prática escolar dividem-se na seguinte estrutura: 1) Tendência liberal tradicional; 2) Tendência liberal renovada progressiva; 3) Tendência liberal renovada não-direta; 4) Tendência liberal tecnicista. A tendência liberal tradicional sustenta a ideia de que a escola tem por função preparar os indivíduos para o desempenho de papéis sociais, de acordo com as aptidões individuais. Devido a essa compreensão, as diferenças entre as classes sociais não são consideradas, pois, embora a escola passe a difundir a ideia de igualdade de oportunidades, não leva em conta a desigualdade de condições. Essa tendência é uma justificação do ser passivo, enquanto o adulto tem 0 poder de escolher o que é bom e o que serve para a sua educação.

Contrariando o didatismo presente na prática pedagógica de alguns educadores, os Parâmetros Curriculares Nacionais para a Língua Portuguesa afirmam que:

A questão do ensino da literatura ou da leitura literária envolve, portanto, esse exercício de reconhecimento das singularidades e das propriedades compositivas que matizam um tipo particular de escrita. Com isso, é possível afastar uma série de equívocos que costumam estar presentes na escola em relação aos textos literários, ou seja, tratá-los como expedientes para servir ao ensino das boas maneiras, dos hábitos de higiene, dos deveres do cidadão, dos tópicos gramaticais, das receitas desgastadas do "prazer do texto", etc. Postos de forma descontextualiza$\mathrm{da}$, tais procedimentos pouco ou nada contribuem para a formação de leitores capazes de reconhecer as sutilezas, as particularidades, os sentidos, a extensão e a profundidade das construções literárias. (BRASIL, 1997, p. 30).

sistema capitalista. Difunde a ideia de igualdades de condições. Os procedimentos didáticos, as relações professor/aluno não têm nenhuma relação com o cotidiano do aluno e muito menos com as realidades sociais. 
Contudo, com a predominância, na maioria das escolas, de um modelo educacional tradicionalista, é improvável o uso da literatura sem uma finalidade pedagógica, pois a premissa é normalmente pautada em avaliações e resultados. Sendo assim, o autoritarismo impossibilita que seja criado um ambiente descontraído, harmonioso e favorável à prática da leitura-prazer.

Um dos fatores que consideramos relevante para ser discutido nesta pesquisa é o modelo de produção capitalista em que vivemos, pois em grande medida este influi diretamente na qualidade e na prática da leitura literária de qualidade, que está se tornando cada vez mais escassa. Essa afirmação é feita, pois a todo o momento somos bombardeados pelos apelos da mídia consumista, voltados à alienação e à manutenção de uma sociedade acrítica. A partir disso, muitas publicações sem conteúdo literário qualificado são despejadas no mercado editorial, e, infelizmente, devido à falta de tempo e mesmo de conhecimento de muitas famílias, estas atendem aos apelos da indústria cultural e das crianças que são atraídas e convencidas com facilidade pelo marketing inteligente e propagandas bem elaboradas a comprar livros que deixam muito a desejar em relação à qualidade literária que, embora seja evidente e elementar, merece muita atenção no momento da escolha.

Desse modo, torna-se necessário que os adultos estejam atentos aos seguintes aspectos do livro:
1) Elementos intrínsecos: os livros devem atender às necessidades fundamentais da infância. Os assuntos devem corresponder ao mundo da criança e seu interesse;

2) Qualidades intrínsecas: os livros devem garantir objetividade nas informações e introdução de valores sociais como justiça, paz, liberdade, igualdade, solidariedade. Nunca transmitir ideias preconceituosas, racistas de qualquer espécie nem imagens e conceitos pejorativos, elitistas e discriminatórios;

3) Aspectos formais: os livros devem possuir qualidades estéticas, ou seja, devem ser artísticos porque os leitores são crianças, não pode haver negligência ou vulgaridade. Logo, devem contribuir para a educação da sensibilidade, criticidade e criatividade, tendo uma boa apresentação, ilustração, composição, espaçamento e outros dados ${ }^{3}$.

É importante mencionar que não pretendemos nos ater no assunto família, mesmo esta tendo grande influência no estímulo da leitura literária da criança. A ideia é nos determos no papel da escola e do professor, que tem (ou deveria ter) responsabilidade, conhecimento, propriedade e ferramentas para entender e trabalhar com a literatura infantil de modo diferenciado e qualificado. Am-

\footnotetext{
${ }^{3}$ Estas informações estão mais detalhadas em: GOÉS, M. Lúcia Pimentel. Introdução à literatura infantil e juvenil. São Paulo: Pioneira, 1984, p. 23-24.
} 
bos, escola e professor, podem primar pela inserção cada vez maior na sala de aula, de uma literatura de concepção emancipadora, ao invés de uma literatura mantenedora, que não contribui para a formação de nossas crianças.

Sandroni e Machado ainda ressaltam que "a escola também ocupa um grande espaço na vida social da criança e, dependendo da habilidade dos professores, poderá ter uma enorme influência no gosto pela leitura" (SANDRONI; MACHADO 1998, p. 21). Contudo consideramos que, para isso, o professor precisa ser um apreciador e um conhecedor de literatura. Necessita ter uma base sólida de conhecimento sobre a literatura infantil para, dessa forma, poder difundir nas crianças o gosto e o apreço pela leitura.

Sendo assim, tomando como base os livros que têm à disposição na escola, na sala/ espaço de leitura, na biblioteca escolar ou municipal, no acervo pessoal e na internet, esta última tendo se destacado nos dias atuais como mais um recurso para o trabalho com a literatura infantil, o professor pode incluir em suas aulas um momento para apreciação da leitura literária. Ou seja, uma leitura que permite a construção de uma realidade paralela, mas não dissociada, e apoiada na imaginação, que aponte a realidade com uma roupagem nova. Uma leitura que se relaciona com a arte da palavra, com a estética e com o imaginário, permitindo ao leitor adquirir uma nova visão de mundo, com novas possibilidades de interpretação da realidade.
Desse modo, Costa (2007) comenta que o professor deve sempre promover uma literatura de qualidade para que a criança possa sentir-se premiada ao ler, seja porque aprendeu, seja porque venceu obstáculos, seja porque se emocionou com os poemas ou narrativas que leu. Ou, como afirma Oliveira (1996), cabe ao professor zelar por trabalhar em sala de aula, com uma literatura infantil que possibilite o intercâmbio com a cultura e com o conhecimento do aluno, pois, enquanto produto cultural, esta interfere na cultura do aluno, reforçando-a, negando-a ou provocando nele, de diferentes formas, novos conhecimentos e uma ressignificação de sua visão de mundo.

Ou, ainda, como defende Frantz (2005), o professor deverá incentivar uma leitura que assume a função crítica e social, proporcionando ao indivíduo, seja esta criança, jovem ou adulto, o direito a um posicionamento próprio diante da realidade. Uma literatura que age no sentido da humanização, ampliando no indivíduo a capacidade de pensar, sentir e interagir nas relações sociais do seu tempo e com as questões da sociedade. Uma literatura que possa superar o que Paulino (1997) denuncia como desgosto que os educandos aprendem a ter pelos livros, que são obrigados a ler na escola, e que em nada acrescenta para o seu crescimento cultural, o que Sandroni e Machado reforçam com a seguinte afirmativa:

As crianças estão sendo con- 
dicionadas a livros que têm seu uso limitado à escola e, às vezes, a outros produzidos em série, sem qualquer conotação intelectual ou artística. Os temas são tratados de maneira repetitiva que limita o leitor, a um círculo sem variedades, nem abrindo, nem ampliando seus interesses. (SANDRONI; MACHADO, 1998, p. 31).

Infelizmente essa literatura de concepção mantenedora, como bem postula Costa (2007), só constrói no pensamento da criança, que ler é somente buscar informações já percebidas. É confirmar, manter o que já foi colocado. É reproduzir, sem qualquer ação, participação e questionamento. É a literatura transformada em ferramenta e recurso para atingir determinados fins.

Enfim, todas as questões tratadas até aqui, por meio do referencial bibliográfico estudado, são extremamente importantes e esclarecedoras e serão investigadas em uma instituição de ensino pública da Baixada Fluminense, RJ, que trabalha com os anos iniciais do Ensino Fundamental em uma turma de $5^{\circ}$ ano. O município e o nome da escola não serão divulgados a pedido da instituição.

\section{PERCURSOS METODOLÓGICOS}

Para conhecer e compreender a concepção do educador sobre o uso da literatura infantil, e analisar a influência dessa concepção em sua prática pedagógica com as crianças, foi primeiramente necessário um estudo teórico aprofundado sobre literatura infantil nas séries iniciais e o papel do educador como mediador do processo de aprendizagem, sendo o levantamento bibliográfico o primeiro passo para a construção metodológica do projeto de pesquisa.

Sendo assim, consideramos importante descrever e esclarecer como foram desenvolvidos os passos metodológicos da pesquisa, que funcionou da seguinte maneira: 1o passo: A partir das leituras empreendidas e fichamentos, foi possível a construção de quatro questões norteadoras, que guiaram a parte empírica da pesquisa. A partir disso, foi decidido que as fontes de informação basear-seiam nos estudos bibliográficos, como também nas evidências empíricas, com a aplicação das seguintes técnicas de coleta de dados: análise documental, observação sistemática e entrevista semiestruturada; 2o passo: De acordo com as questões norteadoras e com a composição da amostra de pesquisa, foi realizada a construção preliminar da entrevista com o implementador de leitura, sujeito da pesquisa; 3o passo: Quanto aos instrumentos para a coleta de dados, a primeira parte foi realizada na análise dos documentos da escola, como o Projeto Político Pedagógico (PPP) e o Plano de Ação de Implementação de Leitura, com o intuito de observar e comprovar a presença da literatura infantil, bem como sua concepção, no planejamento da escola e do professor.

O segundo passo da coleta de dados foi a entrevista, que se deu pela necessidade de um contato mais pessoal 
e interativo com o sujeito da pesquisa, ou seja, com o implementador de leitura nas Séries Iniciais do Ensino Fundamental. Sendo assim, Oliveira (2007, p. 86) diz que:

A entrevista é um excelente instrumento de pesquisa por permitir a interação entre pesquisador(a) e entrevistado(a) e a obtenção de descrições detalhadas sobre o que se está pesquisando.

Dessa forma, foi escolhida a entrevista semiestruturada, ou entrevista por pautas, pois, segundo Gil (1999, p. 120): "A entrevista por pautas apresenta certo grau de estruturação, já que se guia por uma relação de pontos de interesse que o entrevistador vai explorando ao longo de seu curso". Permite, assim, uma flexibilidade no diálogo entre o pesquisador/ pesquisado e a análise dos fatos com maior profundidade.

Assim, Gil (1999) recomenda o trabalho com entrevistas semiestruturadas nas situações em que os pesquisados não se sintam à vontade para responder à entrevista, fazendo, dessa forma, poucas perguntas de modo a deixar o entrevistado falar livremente sobre o assunto pesquisado.

A terceira parte da pesquisa de campo foi realizada com observação direta, também conhecida como observação estruturada ou sistemática. Sua escolha justifica-se pela necessidade de observar a realidade do problema/ tema pesquisado na sua origem, sendo necessário um planejamento prévio para que a coleta de dados da observação esteja em consonância com os objetivos da pesquisa. Sobre isso, Oliveira (2007, p. 80) diz que "[...] desta forma é possível observar os atos em seu contexto e circunstâncias em que se verificam as atitudes e reações [...]". A partir disso, a observação foi realizada nas aulas de implementação de leitura, sendo estas efetivadas uma vez na semana com duração de 50 minutos. A pesquisa foi realizada por um bimestre letivo, incluindo-se os dias disponibilizados para a coleta dos documentos e entrevista.

Cabe destacar que a ordem da coleta de dados foi planejada intencionalmente para que a partir da leitura prévia dos documentos e da realização da entrevista, os dados e informações coletados pudessem direcionar a observação em sala de aula, evidenciando ou não sua veracidade, e relacionando a teoria com a prática.

\section{APRESENTAÇÃO DOS RESULTADOS}

Como citado na metodologia, o primeiro passo que foi dado para a realização da pesquisa de campo foi a análise dos documentos escolares pertinentes à pesquisa, ou seja, o Projeto Político Pedagógico (PPP) e o Plano de Ação de Implementação de Leitura.

Desse modo, na leitura do PPP, pudemos encontrar a concepção de educação progressista, na qual, de acordo com o documento, admite-se o homem como sujeito de sua própria 
história, capaz de interagir dialeticamente com seus semelhantes, com os conhecimentos e com o mundo que o rodeia. No PPP foi afirmado, por diversos momentos, que a instituição escolar tem o intuito de formar indivíduos críticos e ativos socialmente. Entre os referenciais teóricos mais citados, encontramos Vygotsky, Libâneo, Edgard Morin, Paulo Freire entre outros. No entanto a vigência do PPP com que tivemos contato era antiga e não correspondia ao ano vigente; dessa forma, embora estivesse contido no documento projetos e eventos realizados pela comunidade escolar como, por exemplo, a cidadania através da leitura, não foi possível verificar se/e como ocorreram tais projetos/eventos.

Assim, partimos para leitura e análise do Plano de Ação de Implementação de Leitura, que é peça fundamental para a sistematização da pesquisa. O plano de Ação da escola apresenta previamente a luta da educação brasileira contra o analfabetismo e as dificuldades dos educandos em dominar o código escrito. Faz-se referência a questões como o analfabetismo funcional e o letramento, que, aos poucos, foram tomando evidência na educação brasileira e que, em grande medida, propiciaram o desenvolvimento e aprimoramento de novas práticas e concepções pedagógicas. Segundo o documento, nessa nova compreensão de educação pautada no letramento, não basta somente o domínio técnico da leitura e da escrita, mas torna-se necessário fazer com que a leitura e a escrita façam sentido para os educandos, propiciando assim ressignificações e sentido, abrindo portas para a compreensão do mundo.

O Plano de Ação é de postura crítica e progressista, que, segundo o documento, aponta para o protagonismo dos educandos e tem como base referencial Libâneo, Luckesi e Freire, assim como os parâmetros da Lei 10153/03, que implementa a Política Nacional do Livro, o Plano Nacional do Livro de Leitura, esforço conjunto dos Ministérios da Educação e da Cultura e do Projeto da Implementação da Leitura da Secretaria Municipal de Educação do município pesquisado.

O objetivo geral do Plano de Ação é promover o desenvolvimento do gosto e do hábito da leitura na escola observando a construção de aprendizagens significativas e do desenvolvimento da criticidade pelos educandos de modo a favorecer uma inserção social mais humana, consciente, autônoma e responsável, sendo o documento em primeiro momento coerente em suas propostas de ação.

Um fato curioso e importante que foi destacado no Plano de Ação refere-se ao reconhecimento da não existência na escola de uma sala de leitura ou uma biblioteca, para a difícil tarefa de favorecer o desenvolvimento do gosto e do hábito da leitura pelos educandos. Fato incomum de ser destacado em um documento escolar, mas que nos deixou entusiasmados, pois demonstrou que a escola tem e quer compromisso com o trabalho proposto. 


\subsection{Entrevista com o educador}

Como foi apresentado no capítulo da metodologia, a entrevista foi o terceiro passo da coleta de dados, por isso preferimos realizá-la posteriormente às observações para que pudesse confrontá-la com a realidade da prática observada em sala de aula.

Dessa maneira, consta ressaltar que fomos muito bem recebidos pelo entrevistado, que é pedagogo formado também no magistério e pós-graduado em gestão, administração, supervisão e planejamento educacional, tendo trabalhado por algum tempo na área de gestão, e atuando como professor por 24 anos. Durante a entrevista, ele se mostrou bastante entusiasmado com o seu trabalho e com os projetos que estavam em andamento: Fotonovela; Sonhando Pelos Escritos de Sergio Caparelli, e os que estavam para vigorar, como o Projeto contação de histórias. Quando perguntado sobre como acontece seu trabalho na escola, o professor disse que o projeto de implementação de leitura teve início há um ano e meio, e que ele atende atualmente nove turmas durante o tempo de 50 minutos semanais. Todavia ressaltou que, por um ano, atendeu as dezoito turmas da instituição escolar sozinho, o que o impossibilitava de realizar um trabalho eficiente, pois tinha que alternar as turmas semana sim e semana não, e, em alguns casos, devido a feriados, conselhos de classe e reuniões, uma turma só era atendida uma vez ao mês.
No entanto disse-nos que esse problema estava solucionado, pois "desviaram" de função uma professora para auxiliar no trabalho de implementação de leitura. Agora cada um educador atende a nove turmas respectivamente. Quanto aos investimentos que são feitos para o trabalho da implementação de leitura, disse-nos que a verba da Secretaria de Educação para a formação dos educadores é bastante satisfatória, visto que estão em constante formação em serviço através de palestras, rodas de conversa, dentre outros.

No constante aos recursos financeiros destinados à aquisição de livros e infraestrutura da escola, relatou que é nulo, ou seja, é a escola que, com muitas dificuldades no início do ano de 2013, com recursos próprios, adaptou um espaço de leitura que, na verdade, é um ambiente multimeios. Todavia seria, a princípio, uma sala de informática, que nunca funcionou. Dessa forma, a escola adquiriu algumas estantes e alocou o acervo de livros do Programa Nacional Biblioteca na Escola (PNBE) e outros livros enviados pelo Fundo Nacional de Desenvolvimento da Educação (FNDE) e também do Programa Nacional de Alfabetização na Idade Certa, (PNAIC) para esse espaço.

Foi ressaltado que os professores, incluindo ele, não têm autonomia para decidir e escolher os livros que compõem o acervo da escola. Quando perguntado sobre sua relação com a literatura infantil e como ele vê a relação dos professores da escola com 
a literatura infantil, disse-nos que sua relação é intensa e que gosta muito de trabalhar com literatura, mas que a relação dos professores de sala de aula é bastante complicada; relatou-nos que ficou evidente, principalmente no ano anterior, quando o trabalho de implementação de leitura era realizado com a participação dos professores, e ele pôde perceber que era fato que, mesmo com textos mais simples que poderiam ser trabalhados em sala de aula, inexistia um trabalho que poderia desenvolver o hábito e o gosto pela leitura.

Observamos que a atitude deles é muito, muito tecnicista, só se preocupam em passar o texto para os alunos copiarem. Pouquíssimas questões que envolvem autor, título, personagens, é de uma forma objetiva, seca, técnica, behaviorista mesmo. E a implementação de leitura acredita que o trabalho com o texto ultrapassa isso, é claro que tem aspectos técnicos que devem ser observados em uma obra, mas você tem que fazer o possível para a imaginação da criança fluir. Se a imaginação da criança flui no trabalho com o texto ou o livro paradidático, as possibilidades para ele desenvolver o gosto pela leitura são muito maiores. Agora, se for aquela coisa chata porque tem que fazer o dever, a prova, o teste simples e puramente, ai não significa que os resultados serão positivos (fala do professor).

Quanto aos avanços que ele pôde identificar na formação da criança, disse-nos que mesmo nas turmas com mais problemas de aprendizagem na escola, todas gostam muito de participar da implementação de leitura e que o trabalho com a arte mexe muito com as crianças. Falou-nos também que, pelo menos nas aulas de leitura, foi verificada uma melhoria na aprendizagem e atenção das crianças. Todavia considera que o projeto é em longo prazo e que as possibilidades ainda estão em aberto.

\subsection{0 espaço de leitura}

As observações da pesquisa foram realizadas em uma turma de 50 ano do Ensino Fundamental, com aproximadamente 30 alunos frequentes, na sala de aula regular, pois não foi permitido acompanhar as aulas na sala de multimeios, nem tampouco a pesquisa com um maior número de turmas da escola, como a princípio seria de interesse para a pesquisa. Quanto à localização, a escola situa-se em uma região de periferia, com a maioria das crianças provenientes das classes populares. Quanto ao modo e duração das observações, estas foram realizadas durante as aulas de implementação de leitura que têm duração de 50 minutos, uma vez por semana, durante um bimestre letivo.

O espaço da sala de aula regular é de aproximadamente $40 \mathrm{~m}^{2}$ e não possui livros literários disponíveis para as crianças, possui uma estante para a professora com alguns materiais de uso da educadora e um armário com alguns livros didáticos. No entanto, mesmo não sendo permitida a realização da pesquisa de campo dentro do espaço de leitura, cabe destacar alguns aspectos deste, 
pois é o local onde se encontram os livros para leitura da literatura e para empréstimo, e onde acontece a maior parte do atendimento com a literatura para com as crianças.

Como relatado no próprio Plano de Ação de Implementação de Leitura da escola, o espaço é adaptado e insuficiente para acomodar todas as crianças confortavelmente, pois, além de servir para projetos como o Mais Educação, é também depósito de materiais pedagógicos, sala de reuniões, e possui um constante fluxo de pessoas adentrando a todo o momento. Outro fator são os das mesas fixas de mármore que, a princípio, serviriam para as aulas de informática e que nunca foram usadas, o que atrapalha a visão e a circulação pelo espaço. Não atende assim as especificidades que um ambiente destinado à prática de leitura deveria proporcionar.

Ainda assim, o educador tenta superar as dificuldades utilizando microfone sem fio, e procurando colocar as crianças o mais próximo possível dele. Os livros ficam expostos em sete estantes a uma altura onde as crianças podem alcançar com as próprias mãos. Entretanto o empréstimo dos livros para a leitura que é feita em casa pode ser realizado somente um dia na semana, quando o implementador responsável pelo acervo atende menos turmas.

\subsection{As estratégias}

Neste momento iremos descrever os projetos que estavam sendo desenvolvidos na turma, exatamente como foi observado na sala de aula.

Durante o período de observação com a turma, estava acontecendo o projeto Fotonovela. Em princípio não entendemos o porquê de se chamar fotonovela, mas preferimos observar ao invés de perguntar ao educador, pois poderia influenciar em alguma atitude. Com o desenrolar da aula, compreendemos que o trabalho com a fotonovela era realizado a partir do livro "O Guarani" de José de Alencar, que era lido paulatinamente em viva voz pelo educador, de modo que a cada semana era lida uma parte. O livro possuía algumas ilustrações no início de cada capítulo e, certamente, por isso que era utilizado o termo fotonovela. Ficamos um pouco surpresos, pois pensávamos que a estratégia da fotonovela seria voltada à construção de uma novela pelas crianças através de imagens produzidas por elas, ou algo mais dinâmico. No entanto tratava-se de contação de história pelo educador. Após o término do livro $O$ Guarani, a mesma proposta seria adotada com base no livro O Alienista de Machado de Assis. Foi percebido que as duas obras utilizadas nas fotonovelas eram adaptadas e simplificadas.

Outro projeto que estava sendo desenvolvido concomitante com o da fotonovela foi o Sonhando pelos escritos de Sergio Caparelli, nos quais as crianças conheceriam um pouco sobre a vida e obra de Caparelli. A estratégia para tanto era também de contação de histórias pelo educador. As poesias eram curtas, 
rítmicas e de fácil compreensão. Assim sendo, Rouxel (2013) reforça a importância de confrontar os alunos com a diversidade do literário e propor obras nas quais possam ser extraídos ganhos éticos e estéticos, deixando marcas existenciais nos educandos.

Quanto à leitura da literatura nas aulas de implementação, observamos que era sempre o educador que lia o livro, sendo a estratégia de contação de história pelo professor praticamente a única observada durante a pesquisa. Cabe destacar que a escolha da história também sempre partia do adulto. Não foi observada a influência das crianças na escolha das histórias. Desse modo, Dalvi, em Leitura de literatura na escola, afirma que no Ensino Fundamental é importante que:

A criança deixe progressivamente de depender daquilo que o adulto decide contar/ler/ cantar para ela para poder buscar aquilo que deseja ler, daí a importância da biblioteca escolar e do trabalho com diversos gêneros escritos, inseridos em situações socialmente relevantes. (DALVI, 2013, p. 72).

No entanto a escola não possui um espaço de livre acesso para as crianças poderem buscar textos e livros de diferentes composições. Assim, ficam restritas à possibilidade de empréstimo de livros no espaço de leitura apenas uma vez na semana.

Durante as observações, consideramos importante saber a opinião dos educandos sobre as aulas de leitura, conversando informalmente com eles sobre o que pensavam das atividades. De um modo geral, todas falaram que gostavam, mas um depoimento de uma aluna nos deixou intrigados. Quando questionada sobre o que achava das aulas de leitura, ela disse:

Eu gosto mais ou menos, tia. Ele (implementador de leitura) só fala, fala. A professora disse que nós ia brincar, pintar, desenhar, mas não tem nada disso.

Relacionando a fala da aluna com o que está proposto na Coleção Explorando - Literatura (2010), do Ministério da Educação, afirma-se que:

O lúdico e o sensorial, aliados ao emocional, estão no bojo da proposta do professor que, em suas mediações, poderá recorrer a estratégias variadas para obter seus objetivos junto ao leitor infantil. Em vez de insistir no caráter utilitário do texto, o professor há de prover seus alunos com dramatização, contar histórias e resumir filmes baseados em narrativas literárias, recorrer a fantoches, ler com entusiasmo passagens de romances, contos e poemas, enfim, possibilitar que acriança se envolva na miniatura de mundo que é cada livro. Deduz-se daí que a ação do professor torna-se efetiva e afetiva. (BRASIL, 2010, p. 12).

Contudo pudemos perceber que, exceto em uma ocasião, não houve 
nenhuma modificação das estratégias pedagógicas para com a literatura infantil. Nesse sentido, Sandroni e Machado afirmam que, no trabalho com o livro em sala de aula, devem ser constantemente exploradas as expressões oral, escrita, cinematográfica, plástica, fotográfica, gráfica, corporal e musical.

Desde que sejam respeitadas a liberdade e autenticidade de expressão, a experiência é altamente enriquecedora e leva o leitor a penetrar e sentir a história com profundidade. (SANDRONI; MACHADO, 1987, p. 55).

A partir dessa constatação, percebemos um descompasso entre a prática e as propostas do Plano de Ação de Implementação de leitura da escola, porque as estratégias não atenderam, ao menos durante o tempo de observação da pesquisa, às indicações expostas no referido Plano, que, em sua página 11 , preconiza: o incentivo à leitura como prática prazerosa e de entretenimento, utilizando-se de ações lúdicas que aproximem os educandos dos livros e dos textos paradidáticos disponíveis na escola, como também não conseguimos visualizar a efetivação do também proposto pelo Plano, que é o de relacionar a prática da leitura com as mais variadas manifestações artísticas, como o desenho, a pintura, a música, a dança e o teatro, de modo a humanizar essa prática.

Sendo assim, iremos descrever a atividade de desenvolvimento de uma poesia que foi o único momento em que pudemos presenciar uma atividade em que as crianças pudessem, mesmo que limitadas por um tema, expressar sua criatividade. A atividade de desenvolvimento de uma poesia teve como intuito a participação no concurso de poesias que estava sendo realizada nas escolas do município, e o tema foi baseado no poema de Rubem Alves, sobre as escolas que são asas e as escolas que são gaiolas.

Nesse dia, o educador iniciou a aula recitando algumas poesias de Olavo Bilac, como A Boneca e Pássaro cativo, e utilizou o livro Palavras de encantamento, para ensinar como produzir rimas. Feito isto, apresentou o tema gerador da poesia que deveria ser escrita individualmente por cada educando, com base na seguinte questão: Como é uma escola de asas? O educador não fez intervenções na produção escrita das crianças, exceto quanto a dúvidas sobre ortografia, deixando-as escreverem livremente sobre o assunto. Semanas após a execução da atividade foram premiadas as melhores poesias de cada turma, durante uma cerimônia simbólica de formatura para entrada em sala de aula na quadra esportiva. Cada aluno selecionado recebeu um mini kit escolar e teve sua poesia colocada no mural das ações de implementação da escola. Por fim, a poesia eleita como a melhor da escola foi lida no desfile cívico da independência do Brasil.

Em uma visão geral do recorte que foi observado do trabalho do educador, além do já descrito, podemos destacar 
que, em alguns momentos, foram realizadas: a análise das imagens; significado de palavras; aspectos técnicos do texto como autor, ilustrador, personagens; o despertar da curiosidade e interesse das crianças. Era evidente o domínio e a segurança que o educador possuía ao contar as histórias para a turma, demonstrando conhecimento das mais variadas histórias infantis e infanto-juvenis.

\section{CONSIDERAÇÕES FINAIS}

As duas questões-problema que fizeram com que a presente pesquisa fosse desenvolvida foram: o aparente desinteresse das crianças pela leitura literária e as dificuldades dos educadores em formar leitores ativos. Tomamos como ponto de análise a concepção de literatura infantil praticada pelo implementador de leitura que, segundo a entrevista e o Plano de Ação de Implementação de leitura da escola, é de concepção crítica e progressista, mas que de todo modo não orienta as ações pedagógicas com a turma pesquisada. Visto que a pouca variação das estratégias de ensino não abarca a completude de um trabalho de concepção crítica e progressista, em que deveria ser estimulada a atuação das crianças como um ser ativo, e não uma participação passiva e tolhida, como presenciado.

Cabe ressaltar que, mesmo com as dificuldades de infraestrutura e as discrepâncias entre a entrevista, o documento e a prática da sala de aula, consideramos que a escola e o educador se empenham dentro de suas limitações e têm o intuito de aprimorar suas práticas e de desenvolver o gosto pela leitura nas crianças. Todavia o projeto ainda está em consolidação e precisa de investimentos pessoal, de tempo, financeiro, de infraestrutura e de uma avaliação mais concisa e processual da práxis educativa.

No entanto não é pretensão deste trabalho estabelecer uma relação de vítimas ou culpados, mas trazer contribuições para que os professores possam em sua prática provocar nos educandos o desenvolvimento do ato criador, o prazer pela arte, provocando a ousadia e a criatividade. Que a escola como um todo sinta a necessidade de fazer com que a literatura infantil esteja disponível em todos os lugares e para todas as crianças; que seja tornada próxima, compreensível e dialógica.

Concordamos com Resende (2013) quando esta nos diz que:

A escola é menos livre que a sociedade: lida com objetivos e conteúdos inseridos num currículo ou programa. A literatura que ali adentra está submetida a essas necessidades escolares, mas isso não significa que teorias e práticas sejam imutáveis. Ao contrário: a escola, assim como todo elemento de cultura, é histórica, e precisa mudar. (RESENDE, 2013, p. 109).

E é desta mudança que estamos falando: mudança de paradigmas, desmantelamento do modelo de escola tradicional, behaviorista, controladora, linear, punitiva, para uma escola que não 
produz ameaças, que respeita a criança como autora de sua própria história; uma escola participativa que leve em conta o contexto sócio-histórico-cultural das crianças e que avalia sem punir, proporcionando uma educação para além da escola, uma educação para a vida. E acreditamos que a literatura infantil possa ser um dos mecanismos de aproximação de uma educação emancipadora, que possa de fato desenvolver nas crianças a ressignificação do mundo, além da reflexão e da criticidade desde a mais tenra idade.

Dessa forma, através deste recorte sobre as concepções e práticas da literatura observadas e vivenciadas na escola, a pesquisa visou contribuir e auxiliar no planejamento e construção de propostas de trabalho consistentes e provocadoras. De modo algum, este estudo pretende esgotar o assunto. Muito pelo contrário, a ideia é que este artigo contribua para a reflexão sobre o trabalho da literatura infantil na escola, atentando para a complexidade e para as possibilidades do trabalho pedagógico do professor, e também possa suscitar o debate de maneira a provocar outras pesquisas sobre $o$ assunto.

\section{REFERÊNCIAS}

BENJAMIN, Walter. A obra de arte na época de sua reprodutibilidade técnica. In: ADORNO, Theodor W. et al. Teoria da cultura de massa. Tradução de Nelson Coutinho. São Paulo: Paz e Terra, 2000. p. 221-254.

BRASIL. Ministério da Educação. Secretaria de Educação Básica. Coleção explorando o ensino - Literatura: ensino fundamental. Brasília: MEC, 2010.

BRASIL. Ministério da Educação. Secretaria de Educação Fundamental. Parâmetros Curriculares Nacionais: língua portuguesa. Brasília: MEC, 1997.

COSTA, Marta Morais da. Metodologia do ensino da literatura infantil. Curitiba: Ibpex, 2007.

DALVI, Maria Amélia. Literatura na escola: propostas didático metodológicas. In: DALVI, Amélia Maria; RESENDE, Neide Luzia; JOVER-FALEIROS, Rita. Leitura de literatura na escola (Org.). São Paulo, SP: Parábola, 2013.

FERREIRA, Aurélio Buarque de Holanda. Mini Aurélio: o dicionário da língua portuguesa. 8. ed. Curitiba: Positivo, 2010.

FRANTZ, Maria Helena Zancan. O ensino da literatura nas séries iniciais. Ijuí: Unijuí, 2005.

GIL, Antônio Carlos. Métodos e técnicas de pesquisa. 5. ed. São Paulo: Atlas, 1999.

GÓES, M. Lúcia Pimentel. Introdução à leitura infantil e juvenil. São Paulo: Pioneira, 1984.

LIBÂNEO, José Carlos. Adeus professor, adeus professora? Novas exigências educacionais e profissão docente. 10. ed., São Paulo: Cortez, 2007. 
LUCKESI, Cipriano. Avaliação da aprendizagem; visão geral. Entrevista concedida ao Jornalista Paulo Camargo, por ocasião da Conferência: Avaliação da Aprendizagem na Escola, Colégio Uirapuru, Sorocaba, SP, 8 out. 2005.

NERY, Maria Auxiliadora N. F; SILVA, Débora Catarina; FIGUEIREDO, Paulo N. Atividades lúdicas e literatura infantil na prática pedagógica: evidência de uma amostra de escolas no Oeste do Brasil. Revista Brasileira de Estudos Pedagógicos, Brasília, v. 89, n. 223, 2008, p. 576-606.

OLIVEIRA. M. M. Como fazer pesquisa qualitativa. Petrópolis: Editora Vozes, 2007.

OLIVEIRA, Maria Alexandre de. Leitura prazer: interação participativa com a literatura infantil na escola. São Paulo: Paulinas, 1996.

PALO. Maria José; Oliveira, Maria Rosa D. Literatura Infantil: voz de criança. São Paulo: Ática, 2006.

PAULINO, Graça (Org.). O jogo do livro infantil. Belo Horizonte: Editora Dimensão, 1997.

PENNAC, Daniel. Como um romance. Tradução de Leny Werneck. Rio de Janeiro: Rocco, 1993.

PERES, Ana Maria Clark. Desejando o livro: a essência da literatura infantil. In: PAULINO, Graça. O jogo do livro infantil (Org.). Belo Horizonte: Editora Dimensão, 1997.

RESENDE, Neide Luzia. O ensino de literatura e a leitura literária. In: DALVI, Amélia Maria; RESENDE, Neide Luzia; JOVER-FALEIROS, Rita. Leitura de literatura na escola. (Org.). São Paulo: Parábola, 2013.

ROUXEL, Annie. Aspectos metodológicos do ensino da literatura. In: DALVI, Amélia Maria; RESENDE, Neide Luzia; JOVER-FALEIROS, Rita. Leitura de literatura na escola. (Org.). São Paulo: Parábola, 2013.

SANDRONI, Laura C; MACHADO, Luiz Raul (Org.). A criança e o livro: guia prático de estímulo à leitura. São Paulo: Ática, 1998.

\section{SITES CONSULTADOS}

CAPES. Disponível em: <http://www.capes.gov.br/educacao-basica/capespibid>. Acesso em: 24 nov. 2015.

INFOESCOLA. Disponível em: <http://www.infoescola.com/psicologia/behaviorismo/>. Acesso em: 24 nov. 2015.

UFVJM. Disponível em: <http://www.ufvjm.edu.br/site/educacaoemquimica/files/2011/05/TEND\%C3\%8ANCIA-PROGRESSISTA-CR\%C3\%8DTICO-SOCIAL.pdf>. Acesso em: 15 nov. 2015. 


\section{Sobre os autores:}

Jonas Alves da Silva Junior: Doutor em Educação pela Universidade de São Paulo (FE/USP) e Professor Adjunto II da Universidade Federal Rural do Rio de Janeiro (UFRRJ).E-mail: jonasjr@usp.br

Michele dos Santos Melo Fernandes: Graduada em Pedagogia pela Universidade Federal Rural do Rio de Janeiro (UFRRJ) e pesquisadora no Programa Institucional de Bolsas de Iniciação a Docência (PIBID). E-mail: melomichele84@gmail.com

Recebido em janeiro de 2016.

Aprovado para publicação em junho de 2016. 
